\title{
Radioecology studies in the vicinity of a closed uranium mine
}

\author{
B. SModiš* $\check{L}^{*}$ M. ŠTroK ${ }^{\dagger}$ and M. Černe
}

Jožef Stefan Institute - Jamova cesta 39, SI-1000 Ljubljana, Slovenia

\begin{abstract}
Although the influential area of the former uranium mine at Žirovski vrh, Slovenia has been under continuous radiological monitoring, more detailed radioecology studies, focused on assessing mobility and bioavailability of deposited radionuclides, were initiated about five years ago. The mobility of ${ }^{238} \mathrm{U},{ }^{234} \mathrm{U},{ }^{230} \mathrm{Th}$ and ${ }^{226} \mathrm{Ra}$ was studied applying two sequential extraction protocols. The results revealed that both sequential extraction protocols are not comparable as the data obtained are protocol- and radionuclide-dependent. It was found that the most mobile ones were uranium isotopes, followed by ${ }^{226} \mathrm{Ra}$ and ${ }^{230} \mathrm{Th}$. In addition, uptake of particular radionuclides by the wetland plants (Molinia arundinacea, Juncus effusus and Caltha palustris) grown in soils contaminated with seepage waters from the tailings was studied. The plants contained higher levels of ${ }^{238} \mathrm{U},{ }^{226} \mathrm{Ra}$ and ${ }^{230} \mathrm{Th}$ compared to the plants from the control site. Activity concentration of ${ }^{226} \mathrm{Ra}$ was the highest for all three plant species. Activity concentration of natural radionuclides in milk collected from the area of Žirovski vrh was comparable to the reference location, except for uranium where the content was higher. The combined annual effective dose for adults consuming milk from the Žirovski vrh area is $13 \pm 2 \mu \mathrm{Sv} \mathrm{yr}^{-1}$.
\end{abstract}

\footnotetext{
${ }^{*}$ E-mail: Borut.Smodis@ijs.si

${ }^{\dagger}$ E-mail: Marko.Strok@ijs.si

${ }^{\ddagger}$ E-mail: Marko.Cerne@ijs.si
}

This is an Open Access article distributed under the terms of the Creative Commons Attribution License 2.0, which permits unrestricted use, distribution, and reproduction in any medium, provided the original work is properly cited. 


\section{Introduction}

Uranium ore was discovered at Žirovski vrh, Slovenia in 1960 [1]. From that time until 1982, when industrial excavations were started, different research activities, as well as yellowcake production in a small pilot plant were carried on. Two years later, in 1984, industrial yellowcake production from the crushed and milled uranium ore was started and lasted up to 1990. In that year mining and milling activities were stopped by a decree from the Slovenian government. Since then, about 630,000 tons of uranium ore and more than 2.5 million tons of gangue and low-grade uranium ore had been excavated. The process of yellowcake production from the crushed and milled uranium ore included leaching of uranium with $\mathrm{H}_{2} \mathrm{SO}_{4}$. Remains after leaching are so-called uranium mill tailings (UMT). Prior to the deposition in the Boršt waste pile, UMT was filtered on belt filters. The filtrate was recycled and the residue deposited in the Boršt waste pile. UMT contains enhanced levels of all decay products from the ${ }^{238} \mathrm{U}$ decay chain. Activity concentrations in the UMT at Boršt are: $(995 \pm 80) \mathrm{Bq} \mathrm{kg}^{-1}$ for ${ }^{238} \mathrm{U},(3930 \pm$ $580) \mathrm{Bq} \mathrm{kg}^{-1}$ for ${ }^{230} \mathrm{Th}$ and $(8630 \pm 340) \mathrm{Bq} \mathrm{kg}^{-1}$ for ${ }^{226} \mathrm{Ra}$ [2]. UMT waste was covered with a $30-40 \mathrm{~cm}$ thick soil cover and spontaneously overgrown with grass, shrubs and trees.

The first documented organised surveillance of the environmental impact of mining activities dates in 1968 [1]. At the beginning, surveillance was limited to the measurement of uranium, radium, radon and gross beta activity in mine waters and in the Brebovščica stream. As the activities concerned with the operation of the uranium mine were extended, surveillance and monitoring were also extended and in 1984, when the yellowcake production was started, all possible radionuclide transfer paths were continuously monitored (waters, sediments, air, soils, aerosols, gamma radiation and biological materials). Today, twenty years after cessation of the mining activities, the former uranium mine area is completely restored and the Boršt waste pile is remediated. Remediation works included a $2 \mathrm{~m}$ thick soil cover of different densities to prevent radon exhalation and infiltration of rainfall into the piles.

It is believed that after remediation the waste pile will not have any significant environmental impact. However, the pile is situated in the subalpine region with relatively high rainfall and within a relatively densely populated area. Taking into account the long half-lives of the deposited radionuclides as well as the meteorological and geological conditions, it is possible, that in the future radionuclides will migrate out of the waste pile. This could then be a possible threat to the nearby living population. Therefore, it 
is very important to assess mobility and bioavailability of the natural radionuclides present in the pile, both from the radiation protection and the long-term stability viewpoints. For that reason, soil and plant samples from the Boršt waste pile and its surrounding were collected before remediation was started. In addition, milk samples were collected from the nearby living farmers and from a reference location in order to assess their content of natural radionuclides and to investigate a possible effect of past uranium mining activities.

Soil samples were subject to two sequential extraction protocols to be able to identify the mobility of certain radionuclides. Sequential extraction is one of the possible tools for assessing mobility of contaminants in the environment. The aim of performing a sequential extraction protocol is to assess the activity concentration of a specific radionuclide in a certain fraction. Fractions are operationally defined and are reagent dependent. The two most widely used sequential extraction protocols were selected: the Schultz modification of the Tessier protocol [3] and the revised BCR sequential extraction protocol [4]. The first protocol consists of five fractions (exchangeable, organic matter, carbonates, Fe/Mn oxides and residue) and the second one of four fractions (carbonates, $\mathrm{Fe} / \mathrm{Mn}$ oxides, organic matter and residue). It is evident from table I that there are considerable differences between the two protocols; therefore, the results of both protocols were statistically compared. For practical reasons, the Schultz modification of the Tessier protocol will be designated throughout the text as protocol $\mathrm{S}$ and the revised BCR sequential extraction protocol as protocol B.

Several plant species were used for the determination of transfer factors for selected radionuclides. Results were also compared with control sites to identify a possible enhanced uptake of the radionuclides. Radiological exposure of the plants was also assessed using the ERICA Tool [5]due to their constant exposure to tailings waters.

Natural radionuclides in milk samples were analysed and results were compared with the reference location. In addition, the combined annual effective dose for adults and infants consuming milk from the Žirovski vrh area was calculated and compared with the milk from the reference location.

\section{Materials and methods}

\subsection{Sampling and sample preparation}

About $5 \mathrm{~kg}$ of soil sample were collected from four sites in the area of Boršt waste pile at a depth of $0-15 \mathrm{~cm}$. Two of the selected sites were close to 
the outflow of the seepage water, which contained enhanced levels of the natural radionuclides from the Boršt waste pile. It was expected that in these swampy sites the radionuclides could be retained and consequently their activity concentrations be elevated. One site was outside of the waste pile and was not affected at all by it. Therefore, it was chosen as reference site. The last site was on the bottom of the waste pile and represented an UMT soil cover. Pre-treatment of the soil samples was performed according to $[6]$.

The plant samples of Molinia arundinacea, Juncus effusus and Caltha palustris were taken in the summer 2009 from a contaminated marsh, which was permanently flooded with tailing seepage waters. The contaminated marsh was located some tens of metres away from the Boršt tailing pile. Each plant species was taken as a composite sample consisting of about 200 single plants. The control plants, which also represented a composite sample, were taken from the marsh in the vicinity of Ljubljana, the capital of Slovenia.

Four milk samples from the farms close to the former uranium mine and one sample from a reference location were collected. The amount of each sample was $5 \mathrm{~L}$. The milk samples were weighed and subsequently evaporated at $60^{\circ} \mathrm{C}$ until dryness and again weighed to determine the wet mass/dry mass ratio.

\subsection{Sequential extraction procedure}

Both sequential extraction protocols were performed according to the instructions given in the quoted papers $[3,4]$.

\subsection{Radiochemical separation procedure}

The detailed radiochemical separation procedure for the sequential extraction fractions for both protocols is presented in [7] and is therefore only summarized in the following paragraphs.

$\mathrm{U}-232,{ }^{229} \mathrm{Th}$ and ${ }^{133} \mathrm{Ba}$ tracers were added to the solutions that remained after each sequential extraction step in order to determine the radiochemical recovery. Radium and barium were co-precipitated with $\mathrm{PbSO}_{4}$. After centrifugation, the supernatant was stored for uranium and thorium separations. Then the $\mathrm{PbSO}_{4}$ precipitate, which contains ${ }^{226} \mathrm{Ra}$, was dissolved with $\mathrm{NaOH}$ and EDTA and ${ }^{226} \mathrm{Ra}$ was microprecipitated in the form of $\mathrm{Ba}(\mathrm{Ra}) \mathrm{SO}_{4}$. This microprecipitate was then filtered through a $0.1 \mu \mathrm{m}$ filter to prepare a counting source for alpha spectrometry. 
Uranium and thorium were co-precipitated from the supernatant with iron hydroxides adding ammonia and $\mathrm{Fe}^{3+}$ ions. After centrifugation, the precipitate was dissolved with $3 \mathrm{M} \mathrm{HNO}_{3} / 1 \mathrm{M} \mathrm{Al}\left(\mathrm{NO}_{3}\right)_{3}$. Then thorium was separated on TEVA ${ }^{\circledR}$ separation resins and uranium on UTEVA ${ }^{\circledR}$ separation resins. After separation, thorium and uranium were microprecipitated with $\mathrm{NdF}_{3}$ and filtered through $0.1 \mu \mathrm{m}$ filters to prepare a counting source for alpha spectrometry.

The residue, which remained after final extraction step for both protocols, was ashed at $650^{\circ} \mathrm{C}$. Then it was fused with addition of $\mathrm{Na}_{2} \mathrm{O}_{2}$ and $\mathrm{Na}_{2} \mathrm{CO}_{3}$. After that, ${ }^{232} \mathrm{U},{ }^{229} \mathrm{Th}$ and ${ }^{133} \mathrm{Ba}$ tracers were added to determine the radiochemical recovery. Then the sample was digested with $\mathrm{HNO}_{3}, \mathrm{HCl}$, $\mathrm{HF}$ and $\mathrm{H}_{2} \mathrm{SO}_{4}$, and evaporated until dryness. Afterwards the residue was dissolved in diluted $\mathrm{HNO}_{3}$ and processed in the same way as for the other sequential extraction fractions.

The radiochemical separation procedure for plant samples was the same as for the residue in the case of sequential extraction protocols.

For the determination of ${ }^{238} \mathrm{U},{ }^{234} \mathrm{U}$ and ${ }^{226} \mathrm{Ra}$ the dried milk sample was ashed at $650{ }^{\circ} \mathrm{C}$. After that a known amount of ${ }^{232} \mathrm{U}$ and ${ }^{133} \mathrm{Ba}$ tracers were added and the sample was digested with $\mathrm{HNO}_{3}$ and $\mathrm{HCl}$. After evaporation to dryness the sample was dissolved with diluted $\mathrm{HNO}_{3}$ and processed in the same way as the samples from the sequential extraction fractions.

In order to determine ${ }^{210} \mathrm{Po}$ in milk, a known amount of ${ }^{209} \mathrm{Po}$ tracer was added to the dried milk sample. After that the sample was digested with $\mathrm{HNO}_{3}, \mathrm{HCl}$ and $\mathrm{H}_{2} \mathrm{O}_{2}$ and evaporated to dryness. Then the Po was spontaneously deposited on the $\mathrm{Cu}$ disc. A more detailed procedure can be found in [8].

For the determination of ${ }^{210} \mathrm{~Pb}$ in milk, a known amount of $\mathrm{Pb}^{2+}$ ions was added to the dried milk sample. Then the sample was digested with $\mathrm{HNO}_{3}, \mathrm{HCl}$ and $\mathrm{H}_{2} \mathrm{O}_{2}$ and evaporated to dryness. More information about the digestion procedure can be found in [7]. After digestion, the sample was dissolved in $2 \mathrm{M} \mathrm{HCl}$ and $\mathrm{Pb}$ was separated from the other radionuclides on Sr Resins using the procedure described in [9].

\subsection{Measurements}

All counting sources for ${ }^{238} \mathrm{U},{ }^{234} \mathrm{U},{ }^{230} \mathrm{Th},{ }^{226} \mathrm{Ra}$ and ${ }^{210}$ Po were measured on alpha spectrometric systems equipped with passivated implanted planar silicon (PIPS ${ }^{\circledR}$ ) detectors (Alpha Analyst ${ }^{\circledR}$, Canberra). The radiochemical recovery for ${ }^{226} \mathrm{Ra}$ was determined via measurement of the ${ }^{133} \mathrm{Ba}$ tracer on a gamma-ray spectrometer (high purity Ge detector) connected to a 
multichannel analyser (Spectrum Master ${ }^{\circledR}$ 919, Ortec). Pb-210 sources were measured with a low-background gas-flow proportional counter, which was calibrated according to [10].

\subsection{Application of ERICA Tool to the contaminated site}

The ERICA Tool (version May 2009) [5], was applied to the location under study in order to determine the potential environmental risk from ionising radiation to the studied plants due to constant contamination of the site with seepage waters from the tailing pile. The assessment was done with Tier 2 as recommended for lower levels of contamination [11]. Experimental data of soil and plants were used as input data for the ERICA assessment. The environmental risk was evaluated using the default screening value of $400 \mu \mathrm{Gy} \mathrm{h}^{-1}$ as proposed in literature [12-14].

\subsection{Transfer factors}

The transfer factor ( $\mathrm{TF}$ ) is the ratio between the activity concentration in the whole plant ( $\mathrm{Bq} \mathrm{kg}^{-1}$ dry mass of a plant) and the activity concentration in soil ( $\mathrm{Bq} \mathrm{kg}{ }^{-1}$ dry mass of soil) and is used as parameter describing the accumulation of radionuclides [15]. Transfer factors were calculated as ratios of the activity concentration in the pooled plant samples (about 50 plants) and the mean activity concentration in the soils.

\subsection{Complementary determinations}

The macro elements in plants were determined by neutron activation analysis $[16]$.

\section{Results and discussion}

\subsection{Sequential extraction}

The results of the statistical comparison of both sequential extraction protocols are shown in table I. Statistical comparison was carried out according to [17]. As protocol B does not include the exchangeable fraction, the results for exchangeable and carbonate fractions for protocol $\mathrm{S}$ were summed and are presented in table I as carbonate fraction. In the third column of the table, the mean of the differences between the two protocols are presented (mean $(\mathrm{S}-\mathrm{B}))$; in the fourth column, are presented the standard deviations of the differences between the protocols multiplied by a factor of two (2SD); 
Table I: Statistical comparison of the two investigated sequential extraction protocols.

\begin{tabular}{|c|c|c|c|c|c|c|}
\hline Radionuclide & Fraction & $\begin{array}{c}\operatorname{mean}(\mathrm{S}-\mathrm{B}) \\
{[\mathrm{Bq} / \mathrm{kg}]}\end{array}$ & $2 \mathrm{SD}[\mathrm{Bq} / \mathrm{kg}]$ & $\begin{array}{c}\max \\
(\operatorname{aver}(\mathrm{S}, \mathrm{B})) \\
{[\mathrm{Bq} / \mathrm{kg}]}\end{array}$ & $\begin{array}{c}2 \mathrm{SD} / \max (\mathrm{S}, \mathrm{B}) \\
{[\%]}\end{array}$ & Agreement \\
\hline \multirow[t]{4}{*}{${ }^{238} \mathrm{U}$} & Carbonates & 26.3 & 68.6 & 82.0 & 84 & $\mathrm{NO}$ \\
\hline & $\mathrm{Fe} / \mathrm{Mn}$ oxides & -51.5 & 140.5 & 85.3 & 165 & $\mathrm{NO}$ \\
\hline & Organic matter & 12.6 & 40.1 & 367.0 & 11 & YES \\
\hline & Residue & -9.7 & 14.8 & 116.3 & 13 & YES \\
\hline \multirow[t]{4}{*}{${ }^{230} \mathrm{Th}$} & Carbonates & 37.7 & 58.5 & 38.9 & 151 & NO \\
\hline & $\mathrm{Fe} / \mathrm{Mn}$ oxides & -3.1 & 6.7 & 9.9 & 67 & $\mathrm{NO}$ \\
\hline & Organic matter & -21.6 & 64.2 & 42.9 & 150 & $\mathrm{NO}$ \\
\hline & Residue & 31.5 & 90.2 & 417.8 & 22 & $\mathrm{NO}$ \\
\hline \multirow[t]{4}{*}{${ }^{226} \mathrm{Ra}$} & Carbonates & 50.7 & 170.9 & 149.0 & 115 & $\mathrm{NO}$ \\
\hline & $\mathrm{Fe} / \mathrm{Mn}$ oxides & -124.8 & 431.0 & 276.7 & 156 & $\mathrm{NO}$ \\
\hline & Organic matter & 20.1 & 66.4 & 129.8 & 51 & NO \\
\hline & Residue & 56.1 & 141.3 & 321.7 & 44 & $\mathrm{NO}$ \\
\hline
\end{tabular}

in the fifth column, the maximum average values for both protocols are presented $(\max (\operatorname{aver}(\mathrm{S}, \mathrm{B}))$; in the sixth column, the relative standard deviations multiplied by a factor of two are presented $(2 \mathrm{SD} / \max (\mathrm{S}, \mathrm{B}))$; and in the last column, the agreement between the two protocols is presented. The more detailed explanation of the statistical method is given in [17]. It was considered that the results of both protocols are in agreement, if relative standard deviation multiplied by a factor of two is smaller than $20 \%$. This value was chosen, because most of the results had relative expanded uncertainties of about $20 \%$. Looking at the results in table I, one can conclude that both protocols, except for organic matter and residue in the case of ${ }^{238} \mathrm{U}$, are not comparable. This means that results for specific fractions should be used very carefully because they are protocol and radionuclide dependent.

Nevertheless, some general conclusions about the mobility of particular radionuclides in the area of the Boršt waste pile can be drawn. From the experimental results can be concluded that the percentage distribution of the fractions for both protocols in the case of ${ }^{238} \mathrm{U}$ in the swampy site 2 and the reference site are similar. This means that the seepage water, which is flowing nearby is not influencing swampy site 2 . On the other hand, the distribution of the fractions for swampy site 1 is similar to that from the site, which lies on the Boršt waste pile. This indicates that uranium is retained in that site. Similar conclusions can be drawn also for ${ }^{226} \mathrm{Ra}$, where in both 


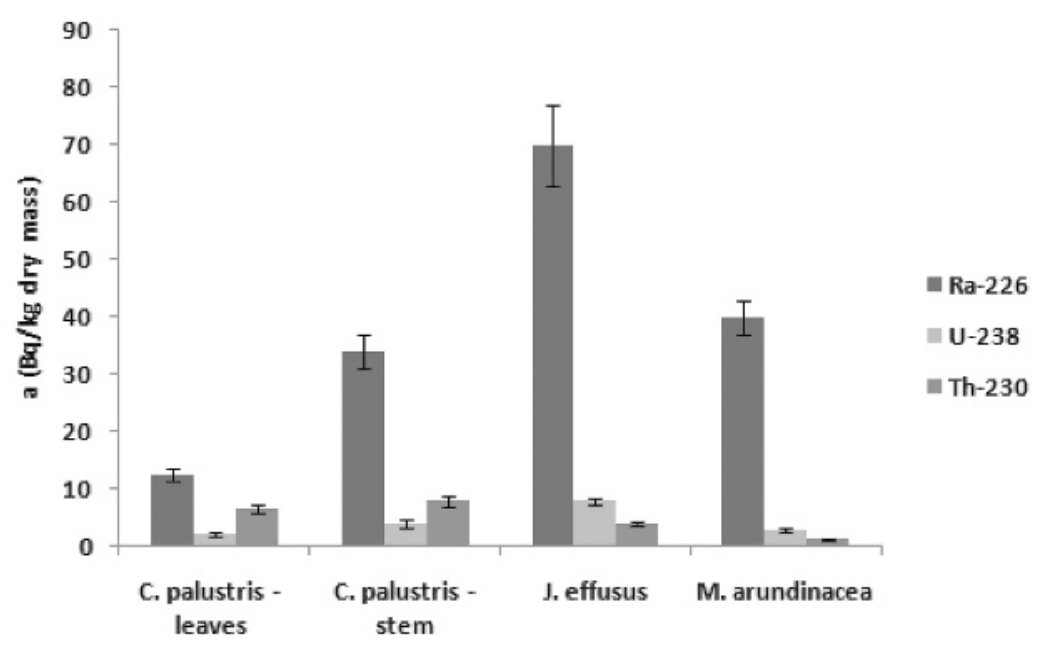

Fig. 1: Activity concentration in plants from the contaminated site (error bars correspond to expanded uncertainties with $k=2$ ).

swampy sites the distribution of the fractions was similar to the reference site, indicating that there was no retention of that specific radionuclide.

It is also revealed that most of the ${ }^{238} \mathrm{U}$ in the site at the Boršt pile and swampy site 1 was found in mobile fractions (70-80\%), whereas in the reference site and swampy site 2 about $90 \%$ of ${ }^{238} \mathrm{U}$ was found in the residue. However, most of ${ }^{230} \mathrm{Th}$ in all samples was found in the residue (50-85\%). At the Boršt pile site, about $60 \%$ of ${ }^{226} \mathrm{Ra}$ was found in the mobile fractions, whereas at the other site most of the ${ }^{226} \mathrm{Ra}$ was found in the residue (60-80\%).

Considering the specific activities found in the UMT [2] and that found in site at the Boršt waste pile, ${ }^{238} \mathrm{U}$ is the most mobile, followed in decreasing order by ${ }^{226} \mathrm{Ra}$ and ${ }^{230} \mathrm{Th}$. It seems that ${ }^{226} \mathrm{Ra}$ mobility is suppressed by high sulphate concentration, which is present in the UMT because it was leached with $\mathrm{H}_{2} \mathrm{SO}_{4}$.

\subsection{Radionuclides in plants}

Activity concentrations of ${ }^{238} \mathrm{U},{ }^{226} \mathrm{Ra}$ and ${ }^{230} \mathrm{Th}$ in the plants from the contaminated site (fig. 1) were relatively low, but evidently higher compared to the control site (fig. 2).

Our results show that the activity concentration of ${ }^{226} \mathrm{Ra}$ was higher in all three plant species and the highest, as expected, in Juncus effusus, which 


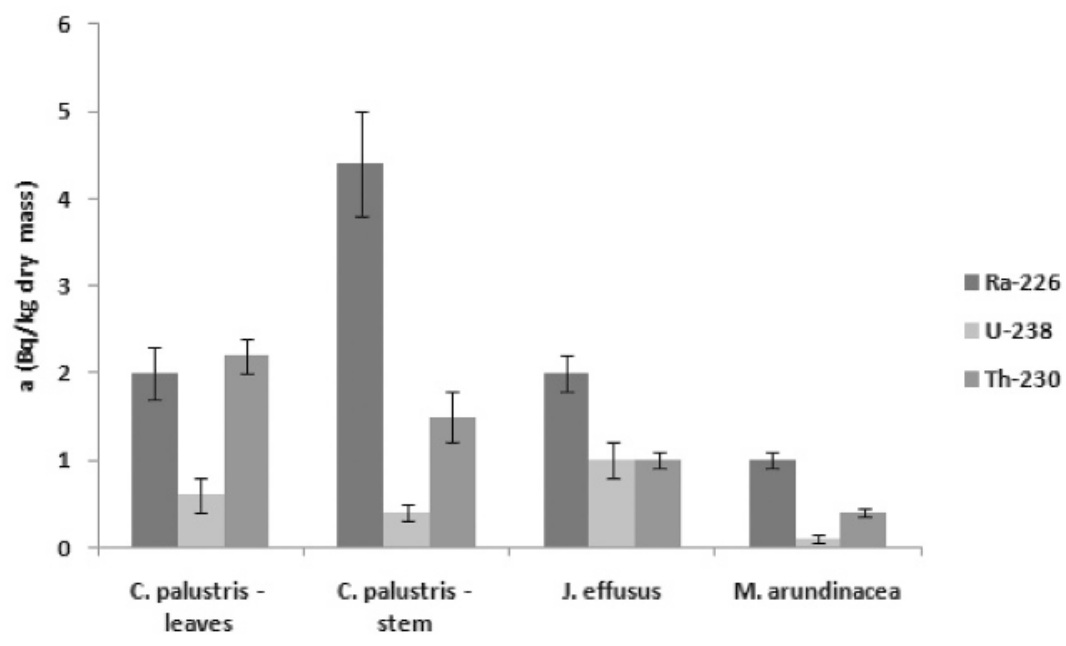

Fig. 2: Activity concentration in plants from the control site (errors bars correspond to expanded uncertainties with $k=2$ ).

is known to accumulate toxic metals [18-20]. Molinia arundinacea contained the lowest activity concentration of ${ }^{230} \mathrm{Th}$. Among the macroelements, only Ca was observed to have a potential influence on the ${ }^{226} \mathrm{Ra}$ activity concentration in Caltha palustris. The observed phenomenon was explained with higher ${ }^{226} \mathrm{Ra}$ and lower $\mathrm{Ca}$ contents found in stems and lower ${ }^{226} \mathrm{Ra}$ and higher Ca content found in leaves (table II). The activity concentration of ${ }^{238} \mathrm{U}$ in the plants was low, probably due to the low ${ }^{238} \mathrm{U}$ content in the contaminated soil.

\subsubsection{Transfer factors}

TF values were the highest for ${ }^{226} \mathrm{Ra}$ in all three plant species. Grass TF values for ${ }^{226} \mathrm{Ra}$ and ${ }^{230} \mathrm{Th}$ were comparable to literature data [21]. No comparison for other TF values was carried out due to lack of data. Transfer factors for the studied radionuclides increase in the following order (table III):

- TF for ${ }^{226}$ Ra: Caltha palustris $<$ Molinia arundinacea $<$ Juncus effuse

- $\mathrm{TF}$ for ${ }^{238} \mathrm{U}:$ Molinia arundinacea $=$ Caltha palustris $<$ Juncus effusus

- TF for ${ }^{230} \mathrm{Th}:$ Molinia arundinacea $<$ Juncus effusus $<$ Caltha palustris 
Table II: Activity concentration of ${ }^{226} \mathrm{Ra}\left(\mathrm{Bg} \mathrm{kg}^{-1}\right.$ dry mass) and content of Ca ( $\mathrm{mg} \mathrm{kg} \mathrm{kg}^{-1}$ dry mass) in Caltha palustris (pooled samples, about 50 plants) from the contaminated site and the control site (expanded uncertainties, $k=2$ ).

\begin{tabular}{ccc}
\hline Caltha palustris-leaves & Caltha palustris-stems \\
\hline \multicolumn{3}{c}{ Contaminated site } \\
\hline${ }^{226} \mathrm{Ra}$ & $12.4 \pm 1.1$ & $34 \pm 3$ \\
$\mathrm{Ca}$ & $16283 \pm 1340$ & $9928 \pm 953$ \\
\hline \multicolumn{3}{c}{ Control site } \\
$\mathrm{Ca}$ & $2.0 \pm 0.3$ & $4.4 \pm 0.6$ \\
$\mathrm{Ca}$ & $23330 \pm 1775$ & $12977 \pm 1150$ \\
\hline
\end{tabular}

Table III: Transfer factors of plants (pooled samples, about 50 plants) from the contaminated site (the activity concentration in $C$. palustris used for the TF calculation is an average of the activity concentration in stems and leaves).

\begin{tabular}{cccc}
\hline \multicolumn{3}{c}{ Contaminated site } \\
\hline $\mathrm{TF}$ & Caltha palustris & Juncus effusus & Molinia arundinacea \\
\hline${ }^{238} \mathrm{U}$ & 0.008 & 0.020 & 0.008 \\
${ }^{226} \mathrm{Ra}$ & 0.026 & 0.078 & 0.044 \\
${ }^{230} \mathrm{Th}$ & 0.020 & 0.011 & 0.003 \\
\hline
\end{tabular}

\subsubsection{Evaluation of environmental risk to plants}

The total absorbed dose rates in the plants were too low to represent an environmental risk due to radio-exposure. They were in the range from $9.7 \times$ $10^{-3}$ to $5.8 \times 10^{-2} \mu \mathrm{Gy} \mathrm{h}^{-1}$ for ${ }^{238} \mathrm{U}$, from $8.0 \times 10^{-1}$ to $3.4 \times 10^{0} \mu \mathrm{Gy} \mathrm{h}^{-1}$ for ${ }^{226} \mathrm{Ra}$ and from $1.2 \times 10^{-2}$ to $3.2 \times 10^{-2} \mu \mathrm{Gy} \mathrm{h}^{-1}$ for ${ }^{230} \mathrm{Th}$. It was expected beforehand that the total dose rates from ${ }^{226} \mathrm{Ra}$ would be the highest ones due to the activity concentration of ${ }^{226} \mathrm{Ra}$ in the soil at the contaminated site.

Environmental risk from ionising radiation to the studied plants was thus negligible as no plant species exceeded the screening value of $400 \mu \mathrm{Gy} \mathrm{h}^{-1}$. The effects of ionising radiation to the studied plants are thus negligible as chronic dose rates below $400 \mu \mathrm{Gy} \mathrm{h}^{-1}$ are not expected to give any significant detrimental or deleterious effects in a wider range of plant communities $[12,13]$. 


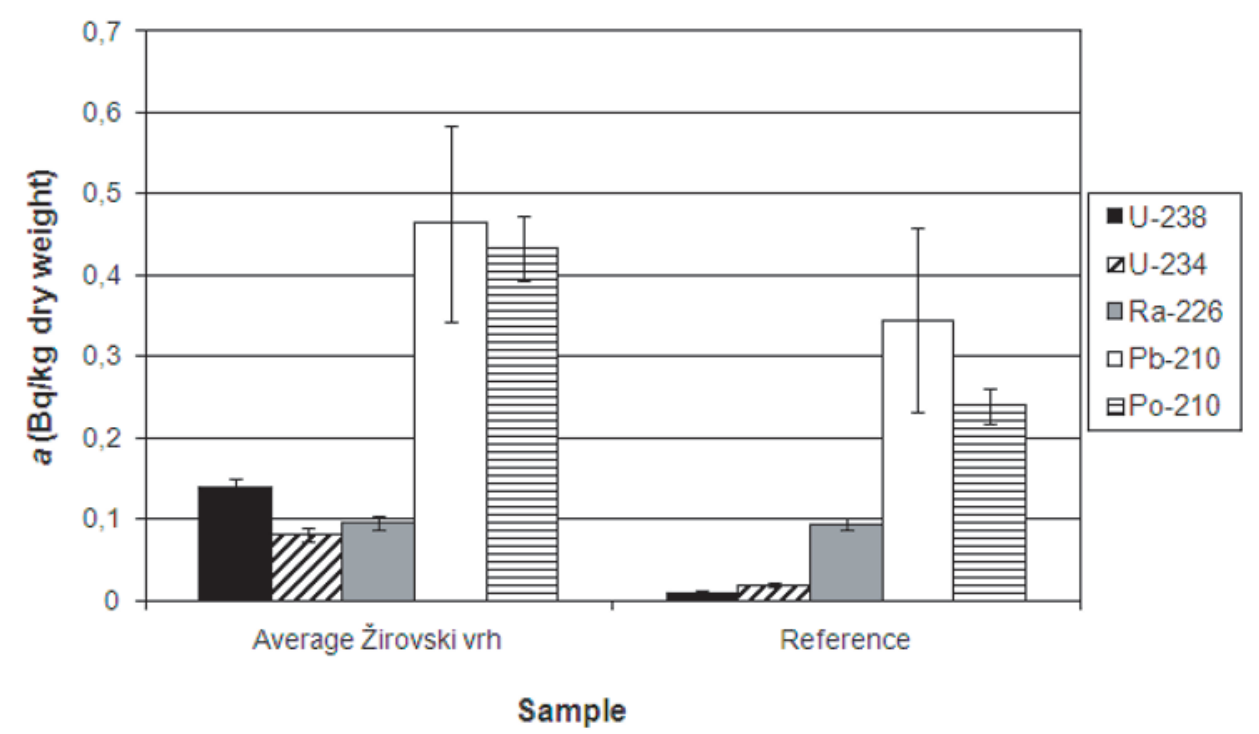

Fig. 3: Activity concentration in milk samples.

\subsection{Radionuclides in milk}

The activity concentration of radionuclides in milk samples is shown in fig. 3 . Average results for four samples collected in the vicinity of the former uranium mine Žirovski vrh are presented. It can be concluded that for uranium and ${ }^{210} \mathrm{Po}$, activity concentrations were higher compared to the reference site, whereas for ${ }^{226} \mathrm{Ra}$ and ${ }^{210} \mathrm{~Pb}$ they were comparable.

The annual effective ingestion dose due to the radionuclides in milk for adults was calculated using eq. (1).

$$
E_{\text {ing }}=h(g)_{\text {ing }} a m .
$$

Where $E_{\text {ing }}$ is the annual effective ingestion dose due to a particular radionuclide in $\mathrm{Sv} \mathrm{yr}^{-1}, h(\mathrm{~g})_{\text {ing }}$ is the committed effective dose per unit of intake by ingestion in $\mathrm{Sv} \mathrm{Bq}^{-1}, a$ is the activity concentration of a particular radionuclide in the sample in $\mathrm{Bq} \mathrm{kg}^{-1}$ dry mass and $m$ is the annual intake of milk in $\mathrm{kg} \mathrm{yr}^{-1}$. The committed effective doses per unit of intake by ingestion for adults, considering a yearly consumption of $122 \mathrm{~kg}$ fresh milk mass, were taken from [22]. It was calculated that the combined annual effective ingestion dose due to the ingestion of milk for adults is $(13 \pm 2) \mu \mathrm{Sv} \mathrm{yr}^{-1}$ for the milk collected in the vicinity of a former uranium mine Žirovski vrh and $(8.7 \pm 1.6) \mu \mathrm{Sv} \mathrm{yr}^{-1}$ for milk from the reference location. The dose at the 
vicinity of a former uranium mine Žirovski vrh is thus $4.3 \mu \mathrm{Sv} \mathrm{yr}^{-1}$ higher than at the reference location. However, taking into account the combined standard uncertainties, differences are statistically insignificant.

The calculations show that the main contributors to the dose are ${ }^{210} \mathrm{Po}$ and ${ }^{210} \mathrm{~Pb}$, which together give almost $95 \%$ of the dose. This is due to the higher committed effective doses per unit of intake and due to the higher activity concentrations of both radionuclides in milk (fig. 3).

\section{Conclusions}

The results of the comparison of two sequential extraction protocols showed that they are not comparable. Therefore, results for specific fractions should be used with care, because they mostly depend on the type of extraction reagent used. This particular study showed that ${ }^{238} \mathrm{U}$ and ${ }^{226} \mathrm{Ra}$ are mostly associated with the mobile fractions at the contaminated sites, while in non-contaminated sites they are mostly present in the residue. ${ }^{230} \mathrm{Th}$ is mostly associated with the residual fractions at all sites. The most mobile radionuclide at the Boršt waste pile is ${ }^{238} \mathrm{U}$, followed by ${ }^{226} \mathrm{Ra}$ and ${ }^{230} \mathrm{Th}$. The mobility of ${ }^{226} \mathrm{Ra}$ in the UMT is suppressed by the high sulphate ion concentrations in it and is therefore similar to ${ }^{230} \mathrm{Th}$.

The results for plants revealed that the seepage tailing waters contribute rather a lot to the activity concentrations of ${ }^{238} \mathrm{U},{ }^{226} \mathrm{Ra}$ and ${ }^{230} \mathrm{Th}$ in plants (J. effusus, C. palustris, M. arundinacea) from the contaminated site. But this does not represent any risk to the environment due to low activity concentration of the measured radionuclides in the plants. The obtained results show the highest values of for ${ }^{226} \mathrm{Ra}$ and the lowest ones for ${ }^{230} \mathrm{Th}$ in all three plant species. The activity concentration was different for each plant species. An influence of the calcium content on the radium activity concentration in plants was only observed in Caltha palustris. Further investigation is required to clarify this phenomenon.

The ERICA-based assessment showed that no environmental risk to the studied plants exists as the total dose rates to the plants are low.

It was also shown that the dose in the vicinity of the former uranium mine Žirovski vrh due to the ingestion of milk for adults is $4.3 \mu \mathrm{Sv} \mathrm{yr}^{-1}$ higher than at the reference location and that most of the dose in milk is due to ${ }^{210} \mathrm{Po}$ and ${ }^{210} \mathrm{~Pb}$, which have the highest committed effective doses per unit of intake among the analysed radionuclides. 


\section{Acknowledgements}

The authors would like to thank the staff of the Rudnik Žirovski vrh company for their cooperation and assistance. The financial support of the Slovenian Research Agency (Grant No. P2-0075) was highly appreciated.

\section{References}

[1] FlorJančIČ A. P., Rudnik urana Žirovski vrh. (Didakta, Radovljica) 2000 (in Slovene).

[2] Križman M., Byrne A. R. and Benedik L., J. Environ. Radioactivity, 26 (1995) 223.

[3] Schultz M. K., Burnett W. C. and Inn K. G. W., J. Environ. Radioactivity, 40 (1998) 155.

[4] Rauret G., López-Sánchez J. F., Sahuquillo A., Rubio R., Davidson C., Ure A. and Quevauviller Ph., J. Environ. Monit., 1 (1999) 57.

[5] Brown J. E., Alfonso A. B., Avila R., Beresford N. A., CopPlestone D., Pröhl G. and Ulanovsky A., J. Environ. Radioactivity, 99 (2008) 1371.

[6] ISO 11464:1994(E), Soil quality - Pretreatment of samples for physicchemical analyses. (International Organisation for Standarisation, Geneve) 1994.

[7] Štrok M. and Smodiš B., Radiochim. Acta, 98 (2010) 221.

[8] Štrok M. and Smodiš B., Nucl. Eng. Des., doi:10.1016/j.nucengdes. 2010.03.035 (2010).

[9] Tavčar P. and Benedik L., Mine Water Environ., 21 (2002) 156.

[10] Štrok M., Repinc U. and Smodiš B., J. Power and Energy Systems, 2 (2008) 573.

[11] Beresford N. A., Brown J.E, Copplestone D., GarnierLaplace J., Howard B., Larsson C-M, Oughton D., Pröhl G. and Zinger I., A Deliverable Report for the Project "ERICA" (Contract No. FI6R-CT-2004-508847) within the EC's VIth Framework Programme. Swedish Protection Authority, Stockholm, (2007a) pp. 82. 
[12] IAEA. Effects of Ionizing Radiation on Plants and Animals at levels Implied by Current radiation protection Standards, Technical Reports Series, No. 332 (IAEA, Vienna) 1992.

[13] UNSCEAR, Report to the general assembly, with scientific annex. United Nations scientific committee on the effects of atomic radiation (United Nations, New York) 1996.

[14] USDOE, A graded approach for evaluating radiation doses to aquatic and terrestrial biota. DOE-STD-1153-2002 (US Department of Energy, Washington, D.C.) 2002.

[15] Gerzabek M. H., Strebl F. and Temmel B., Environ Pollut., 99 (1998) 93.

[16] Jaćimović R., Smodiš B., Bučar T. and Stegnar P., J. Radioanal. Nucl. Chem., 257 (2003) 659.

[17] Bland J. M. and Altman D. G., Lancet, 327 (1986) 307.

[18] Deng H., Ye Z. H. and Wong M. H., Environ. Pollut., 132 (2004) 29.

[19] Archer M. J. G. and Caldwell R. A., Water, Air and Soil Pollut., 167 (2004) 257.

[20] Anawar H. M., Garcia-Sanchez A., Murciego A. and Buyolo T., Environ. Geol., 50 (2006) 170.

[21] Vandenhove H., Olyslaegers G., Sanzharova N., Shubina O., Reed E., Shang Z. and Velasco H., J. Environ. Radioactivity, 100 (2009) 721.

[22] Omahen G., Benedik L. and Repinc U., 2006. Measurements of the radioactivity in the Žirovski vrh uranium mine environment and assessment of its environmental impacts - results for 2005. (Jožef Stefan institute, Ljubljana, IJS-DP-9342) 2006 (in Slovene). 